\title{
Legal Autonomy of Tibet: A Chinese Lawyer's Perspective
}

\author{
Yongmin Bian*
}

\section{Introduction}

The conflict happened on the high plateau of Tibet in the spring of 2008 has drawn much attention of the world on the Tibet issue. The politics-oriented media cover of some foreign countries sharply contradictory to that of China makes it very difficult for ordinary Chinese people to know the actual state of affairs and also creates quite unfriendly and detrimental atmosphere for the peaceful solution of this issue in short time. Open and impartial research and discussion on this issue is necessary and helpful to the final resolution. The Tibet "Government-in-exile" has openly stated its stance and opinions on the autonomy of Tibet, while the Chinese Central Government insists that it is not going to negotiate any'Tibet issue' with the 14th Dalai Lama and his followers except for Dalai Lama' personal future. Since the position of the Central Government on Tibet is very tough, it seems that any autonomy in Tibet beyond the current Chinese law on regional autonomy in ethnic areas is impossible. This paper is dedicated to probing the history and analyzing the current situation of the autonomy of Tibet, and exploring possibilities of changing the current autonomy. Part II introduces the China's administration over Tibet before 1950 when Tibet enjoyed great autonomy. Part III comments on the current system of regional autonomy in Tibet. Part IV discusses possible changes to the current autonomy in Tibet. Due to the big difference between the Central Government of China and the Tibet Government-in-exile, the author concludes that it needs a long way to go to the final solution of the Tibet issue.

\footnotetext{
Associate professor of law at the Law School, University of International Business and Economics in Beijing. LL.B and LL.M (China's Univ. of Law and Political Science), Ph.D. (Univ. of International Business and Economics.) The author may be contacted at: bianyongmin@yahoo.com.
} 


\section{Tibet is the Part of China}

At the beginning of the 13th Century, Genghis Kan established Mongolian Empire. Later he and his successors defeated the Song Dynasty of China and Tibet, and then established the Yuan Dynasty. Since Tibet became part of China in Yuan Dynasty, China has been continually claiming sovereignty over Tibet. But in the past 800 years, the central government of China did not always exercise strong governance over the remote Tibet, especially since the end of Qing Dynasty, when Tibet suffered from the aggression of imperialist powers, which grabbed all kinds of special privileges by means of unequal treaties, subjected Tibet to colonial control and exploitation, and the same time, groomed separatists among the upper ruling strata of Tibet, in an attempt to sever Tibet from China. ${ }^{1}$ Tibet had several chances to separate from China and associate with other states or gain independence, but the Tibetan religious leaders and the Tibetan local government chose to stay with China. When faced with foreign intervention and potential control, Tibet preferred the protection from its China. ${ }^{2}$

The Tibetan people mainly lived in the Qinghai-Tibetan plateau. In history, including the time after Tibet became part of China, for several periods its territory extended to today's Qianghai and parts of Gansu and Yunnan provinces. So today many Tibetan people still lives in Qianghai, Gangsu and Yunnan provinces. In these provinces there are Tibetan autonomous prefectures especially set up for Tibetan compact communities. Today the Tibetan population is about 4.8 millions. ${ }^{3}$ In the past 800 years, Han Chinese assimilated many alien ethnic people including the founders of Qing Dynasty of China, Manchu ethnicity. However, the Tibetan people still keeps its explicit identity until today.

Before the peaceful liberation of Tibet in 1951, the Tibetan people were co-governed by the central government of China and Dalai Lama together. The Central government, "while handling important affairs concerning Tibet, maintained, by and large, the region's original local social setup and ruling body, widely appointed upper-strata ecclesiastic and secular members to manage local affairs, and gave the Tibetan local

1 See China's State Council Information Office, Regional Ethnic Autonomy in Tibet (May 2004), available at http://www.china.org.cn/e-white/20040524/index.htm (last visited on Jul. 25 2008) [hereinafter, The 2004 White Paper], at part I, para.3.

2 John K. Fairbank \& KWAng-ching LiU (ed.), The Cambridge History of China, translated into Chiense by China Academy of Social Science, vol.10 (Late Ch’ing, 1800-1911) 95-97.

3 State Ethnic Affair Commission, Overview of Tibetans, available at http://www.e56.com.cn/system_file/minority/zangzu/zangzu.htm (last visited on Aug. 2, 2008). The 14th Dalai Lama claims, however, that there are 6 millions of Tibetans. According to the researchers of the Cambridge History of China, in 1800, there were no more than 6 millions Tibetans who lived in Tibet and neighbor states and areas. At that time the populations that directly under the governance of Lhasa was about 4 million. See supra note 2 , at 85 . 
government and officials extensive decision-making power." 4 At that time, the Central government maintained troops in Tibet, while the Tibetan local government had its own armed forces. The Tibetan local government also negotiated treaties with neighbor states, but of course the treaties had to be approved by the central government. The current 14th Dalai Lama might miss the more extensive autonomous right that Tibet had enjoyed before 1950. It was very interesting that in history the central government and the Tibetans had different understandings about the relationship between the emperors of China and Dalai Lama. 5 For the Chinese emperors, although Dalai Lama was a very strong spiritual and secular leader, he was subject to the protection of emperors. For Tibetans, the emperors were merely the secular supporters of Dalai Lama. This means for Tibetans the status of Dalai Lama was higher than that of the emperors because in Tibet only Lamas were governors and the secular people had the obligations to provide support to Lamas. Secular person, no matter how powerful or rich, was in subordinate position. 6 The transmission lineage system of reincarnation of the great Lama after his death reflected this subtly different and contradicted understanding. In 1793 a gold urn was bestowed to Lhasa from the emperor of Qing Dynasty for confirming reincarnation of the great lama. Before the coming of the gold urn representing the authority of the central government, the transmission lineage system of reincarnation of a great lama followed the traditional way. The local government of Lhasa had to convince the Tibetans that the Living Buddha was searched and confirmed according to their traditional way, while it had to promise the central government that the Living Buddha was actually confirmed through drawing lots from the gold urn.7 The yield of the local government, according to the international law of 19th century, was one of the evidences recognizing China's sovereignty over Tibet. It is very interesting that after the gold urn was declared to be used for more than two hundreds years, the gold urn itself has become part of the' traditional' way.

Today although many states express their concern about the human rights of the Tibetan people, they recognize Tibet is part of China. Even the 14th Dalai Lama, who claims representing the Tibetans, is not seeking Tibet's independence from China. This being the case, it is not constructive to any peaceful solution of the Tibet issue if one argues that historically Tibet never became part of China till 1951 and challenges China's current sovereignty over Tibet. The Dalai Lama observed that "the long history of the past does not lend itself to a simple black and white interpretation. As such, it is

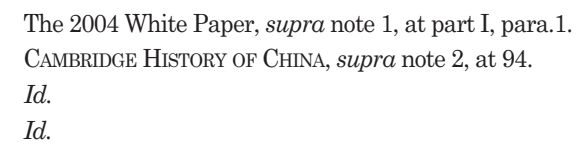


not easy to derive a solution form the past history." 8

\section{The current regional ethnic autonomy in Tibet}

\section{The Establishment of the Tibet Autonomous Region}

When the People's Republic of China announced its foundation in 1949, Tibet was still under the control of Dalai Lama. On May 23, 1951, with the signature of the "Agreement of the Central People's Government and the Local Government of Tibet on Measures for the Peaceful Liberation of Tibet," the Tibetan people got the promise of the'right to exercise regional ethnic autonomy' as one of the conditions to accept peaceful liberation. ${ }^{9}$ The Central Government agreed that the local government of Tibet and its governance would be generally maintained. However, the local government of Tibet was dismissed in 1959 by the Central Government because some people in the upper governing strata wanted to preserve feudal serfdom and refused to carry out democratic reform demanded by the Tibetan people. 10 Soon afterwards a democratic reform of the Tibetan social system was implemented. Lands were re-distributed and some rebelling serf owners were quelled. By the democratic reform, it was proclaimed that the Tibetan people has'acquired the citizens' rights and freedom specified in the Constitution and laws, and swept away the obstacles, in respect of social system, to the exercise of regional ethnic autonomy.'11 But the democratic reform had its negative impacts. Ngapoi Ngawang Jigme, the Vice Chairman of the Chinese People's Political Consultation Conference believed that the democratic reform created the conditions for Culture Revolution to be carried out in Tibet. ${ }^{12}$ The Tibet Autonomous Region was formally founded in 1965. At the very beginning, most Tibetans were very happy with the establishment of the Tibetan Autonomous Region without knowing much about this system. The official White Paper'Regional Ethnic Autonomy in Tibet' (2004) issued by the Information Office of China's State Council did not record the history of the Tibet Autonomous Region from the middle of the 1960s to 1980. Actually the Cultural Revolution starting from 1966 in China almost led the regional ethnic autonomy system to collapse. Many monasteries, mosques and shrines were destroyed and sutras were fired. Monks were forced to give up their religions.

8 See His Holiness of the 14th Dalai Lama of Tibet, available at http://www.dalailama.com/ march10/47thMarch10.html. (last visited on Aug. 2, 2008)

9 See The Establishment and Development of Regional Ethnic Autonomy in Tibet, The 2004 White Paper, part I, paras.5-6.

$10 \quad$ Id. at para.7.

11 Id.

12 Ngapoi Ngawang Jigme, The Truth of Tibet Rebel in 1959, ChInese Tibetan STudies (Zhongguo Zangxue), No.2, 1988 . 


\section{The Development of Tibet}

Compared with that of 50 years ago, Tibet has made great economic and social progress, although it still remains as the least developed area in China. In the first decade after the Tibet Autonomous Region was founded, its economic and social measures were far from perfection. Many lands and properties of monasteries and mosques were confiscated. Disputes and conflicts between different ethnic people, especially between the Han Chinese and the Tibetans, were defined as'class contradictions.' 13 The special natural environment and economy of Tibet was not taken into sufficient consideration in the economic development.

The improvement of people's living standards was mainly achieved during the past two decades. The economic prosperity lays down a solid foundation for the stability of Tibet. The Central Government also justifies the legitimacy of the regional autonomy system mainly based on the fruits of economic development. Following the improvement of transportation, the fast development of trade in commodities and tourism brings new opportunities to the modernization of Tibet and challenges of the protection of the fragile plateau ecology.

Politically the Tibetan people enjoy, according to law, the right of self-governance in their own region and ethnic affairs. Tibetans are appointed or elected to take positions in administrative organs at various levels. According to statistics, at present, Tibetans and people of other ethnic minorities make up $57 \%$ of the chairmen and vice-chairmen of the Tibet Autonomous Region; $69.23 \% 14$ of the members of the Standing Committee of the Regional People's Congress of the Tibet Autonomous Region. However, considering the Tibetan ethnic making up over $95 \%$ of the total population in Tibet, there could be more Tibetan people taking the positions of chairman, vice-chairman, etc. The Communist Party of China also maintains its officials in parallel with all levels of administrative organs. For example, equal with the chairman and vice-chairman of the Tibet Autonomous Region, there are secretary and vice-secretary of the party, who have important powers in decision-making not only limited to the affairs of the party. Most party secretaries in various levels, especially the high level, are not Tibetan or other ethnic minorities.

The freedom to inherit and develop the Tibetan traditional culture and to practice their religious belief is generally respected and protected by law. There are quite different comments from the government and Dalai side on the achievements of the

\footnotetext{
13 State Ethnic Affair Commission, Ten Lectures on Ethnic Affairs of New China (Minzu Wenti ShiJang), at the Sixth Lecture, para.17 (Ethnic Press 2006), available at http://www.seac.gov.cn/gjmw/zwgk/M150901index_1.htm (last visited on Jul. 10, 2008).

14 The 2004 White Paper, supra note 4, at Part II, para.3.
} 
cultural and religious development in Tibet. The government verifies the religious freedom with the fact that today a large number of Tibetans are free to decide whether they believe in Tibetan Buddhism or other religions or atheism. The Dalai side does not dispute in this way. They argue that China's Regulation on Religious Affairs (2004) puts several restrictions on the freedom of religion. For example, Article 12 of the regulation provided that "collective religious activities of religious citizens shall, in general, be held at registered sites for religious activities." In fact with permissions mainly limited to basic teaching and practice of Tibetan Buddhism, masters on Tibetan Buddhism can hardly emerge. This very important religion does not thrive and its impact weakens.

The political, religious and cultural rights and freedom that the Tibetans enjoy have to be understood in the specific background of China and considered as subject to the national interests and social stability. A citizen has the right to decide whether he believes in god or not and which god he believes meanwhile he is expected to love the Communist Party, socialism and the state. Any violation of this is not allowed. For example, the worship of the exiled Dalai Lama may cause trouble. The process to democracy in Tibet has to parallel with the democracy process in the whole China. It is not feasible that Tibet leads the process of democracy in China. The Central Government has committed to enlarge' people's democracy' with a number of concrete policies. 15

The development of Tibet shows that the current regional autonomous system serves as an effective tool to protect the Tibetan people's interests and rights. After the Union of Soviet Socialist Republics was dissolved, the ethnic conflicts in east Europe and other part of the world caused great attention of the Central Government. The Law on Regional Ethnic Autonomy was modified in 2001 to accommodate itself to the new situations resulting from economic and political reform in China. In 2005 the State Council of China promulgated the Provisions of the State Council on the Implementation of Law of the People's Republic of China on Regional Ethnic Autonomy. Many concrete measures and policies were implemented aiming at improving the economic and social development of the ethnic areas. It is sarcastic that the Tibet issue was not so hot in those days when many faults occurred as today when Tibet is in rising prosperity. International elements may help to explain the reasons behind. Taking advantage of the present international background friendly to ethnic movement, Dalai Lama and its exiled government make great efforts in pursuing a higher level of autonomy in Tibet.

15 President Hu Jintao's report delivered at the 17th National Congress of the Communist Party of China (CPC) on Oct. 15, 2007, Documents on the 17th National Congress of the Communist Party of China, People's Press, 2007, Beijing, at 28 . 


\section{Any Changes of the Current Autonomy in Tibet?}

It is good news for China that the Dalai Lama and his supporters have given up the pursuit of independence for Tibet. The later are seeking'meaningful autonomy' or'authentic autonomy' rather than secession of Tibet from China.16 However, there seems to be still some disagreement on where autonomy ends and independence begins. No autonomy should be used as a springboard for independence. It might take many years for both sides to reach a common interpretation on the meaning of a'meaningful autonomy.'

\section{China's experience in dealing with ethnic issue}

The policy of the Communist Party of China on ethnic issues evolved over several decades. At the beginning of the 1920s, influenced by the Union of Soviet Socialist Republics, the Communist Party of China wanted to establish federal states to solve ethnic issues.17 Until the 1930s the Party still acknowledged that the ethnic people had the right to decide whether to become independent from China18 or not. But after Mongolia gained independence from China in 1945, the Communist Party of China denied independence of minorities and chose autonomy as the solution of ethnic issues. ${ }^{19}$ Later the Party explained the reasons. When it was engaged in civil war with Kuomintang, it advocated self-determination in order to gain support from minorities. 'This is completely right at that time.'20 But after the Kuomintang was defeated, for the unification of China, the Party decided that self-determination of minorities should not be emphasized any more. Therefore, initially the Communist Party used ethnic policy as means of winning the power to control China. After it won the power, it started to explore new ethnic policy that can contribute to strengthening the control of the whole China. For a country composed of 56 ethnic minorities, 21 the current policy of ethnic autonomy has proven to be successful for China to deal with ethnic issues.

Split of the state is the biggest worry for the Central Government in dealing with

16 His Holiness the Dalai Lama discusses the recent unrest inside Tibet with the editors of the Financial Times, 1 June 2008, available at http://www.phayul.com/news/article.aspx?id=21454\&t=1\&c=5 (last visited on Jul. 17, 2008).

17 Documentations on Ethnic Issues (Minzu Wenti Wenxian Huibian), Press of Central Party School, Beijing, 1991 , at 18.

18 Constitution Outline of China Soviet Republic (Nov. 1931) art. 166.

19 State Ethnic Affair Commission, supra note 13, at the Fifth Lecture, para. 3.

20 Selected Important Documents since 1949 (Jianguo Yilai Zhongyao Wenxian Xuanbian), vol. I, 24 (Zhongyang Wenxian Chubanshe 1992).

21 The census in 1953 reported that there are more than 400 ethnic minorities. Some ethnic minorities with different names were later proved to be the same minority. After many years' recognition, finally in the census in 1990 it was decided there are totally 56 ethnic minorities. See supra note 13, at the Fourth Lecture. 
ethnic issues. Although theoretically greater autonomy in Tibet may not necessarily lead to the spit of China, it is still very difficult to justify a'greater' autonomy. Since the Central Government has implemented the policy of equality among all ethnic minorities for 50 years, it is difficult to change the policy of autonomy just for Tibet. What will happen if other ethnic minorities raise similar requests following Tibet? A change of autonomous system in Tibet may undermine the fundamental ethnic system of China. Dalai Lama knows this perfectly. 'To the Chinese government it is rather complicated to handle [the Tibet issue]. Their policy regarding Tibet has repercussions in the Xinjiang autonomous region, other autonomous regions, and among the Chinese people themselves.'22 Hence recently Dalai Lama claims'meaningful autonomy' or'genuine autonomy'23 rather than'greater autonomy' or'high level autonomy.' Such change implicates more possibilities for successful negotiations between the Central government and Dalai side, because the current system can become meaningful and real, but it is more difficult to become something greater or higher.

Does Tibet deserve a greater autonomy as what Hong Kong and Macao have? The arrangements for Hong Kong and Macao do not suit Tibet. Before the sovereignty over Hong Kong and Macao was returned back to China, these two territories had been governed respectively by two European States for nearly 100 years. Before they reintegrated with China, the political and social systems of Hong Kong and Macao were quite different from that of the Mainland. China agreed with special arrangements for Hong Kong and Macao for the purpose of stable transmission of sovereignty and minimizing unfavorable impact to the people's life in Hong Kong and Macao. Tibet has been under the governance of China for several hundred years. In the last four to five decades, the political and social systems of Tibet had been transformed to the same as other parts of China with some minor exceptions. The Central Government will not agree to the policy of' one country two systems' to be applied to Tibet.

A state has the sovereign right to administrate its own internal affairs including the governance over its minorities as long as its governance does not violate the international law. Obliged to the responsibility of protecting and respecting the rights of its minorities under the international law, a state can decide its specific way to fulfill its responsibility. The national groups have the right of self-determination. The choice may be independence as a state, association with other groups in a federal state, autonomy or assimilation in a unitary state. 24 The current system of regional autonomy in Tibet is Tibetan choice to exercise their right of self-determination. If implemented well, the

22 See supra note 16.

23 William Yardley, Dalai Lama Says His Aides Are Talking to China, N. Y. TImes, 14 Apr.( 2008)

24 Ian Brownie, Principles of Public International LaW, 553 (Oxford 6th ed. 2003). 
current system of autonomy can well protect the rights and interests of the Tibetan people.

\section{'Meaningful Autonomy'?}

On 1 June 2008 when interviewed by the Financial Times, Dalai Lama said'within the framework of the Chinese constitution, the meaningful realistic autonomy [for Tibetans]. Now, that is our goal.'25 'We are simply asking for meaningful autonomy or genuine implementation, [of] what the Chinese government states [as] the minorities' right, particularly in a white paper about the policy of the minorities. Many detailed rights are mentioned there. [If] all these points are implemented on the spot faithfully, then it's sufficient.'26 These are very reasonable demands at least at the first glance.

First, meaningful autonomy has to be carried out within the framework of the current Constitution of China. Article 4 of the 1982 Constitution stated, '...[R]egional autonomy shall be practiced in areas where people of minority nationalities live in compact communities; in these areas organs of self-government shall be established for the exercise of the right of autonomy...' The Constitution confirms that the minorities live in compact communities have the right of autonomy. However, it failed to specify the contents and scope of the right. In 1984 China promulgated the Law of Regional National Autonomy, which defined the right of autonomy in detail. In 2005 the State Council published the White Paper on Regional Autonomy for Ethnic Minorities in China, 27 which further summarized and elaborated the system of regional autonomy and right of autonomy. If the Dalai side could agree to a meaningful autonomy in conformity with the Constitution and law on regional autonomy, the negotiation between the Central Government and Dalai Lama might be less difficult. From Dalai Lama's words that'We are simply asking for meaningful autonomy or genuine implementation...' we may deduce that the effective and full implementation of the existing laws might satisfy his expectations even without changing the current system.

Second, improvement and development of the current autonomy in Tibet is possible. The Central Government did not declare that its governance in Tibet is so perfect that nothing needs to be changed. On the contrary, it recognized that'regional ethnic autonomy has only been instituted in Tibet for a short time, and it needs to be improved and developed in the course of implementation.'28 In practice it seems easier for the

\footnotetext{
25 See supra note 16.

26 Id.

27 State Council Information Office, The White Paper on Regional Autonomy for Ethnic Minorities in CHINA (Feb. 2005), available at http://english.peopledaily.com.cn/whitepaper/ethnic_minorities_2005/ ethnic.html (last visited on Aug. 1, 2008).

28 The 2004 White Paper, supra note 1, at part V, para.3.
} 
Central Government to give some commitments in economic and social development in Tibet, but it might be more disputable in the dimensions of politics, culture and religion. To find what needs to be changed is the common work for the Central Government and the Dalai Lama side. However, the precondition is that biased propaganda must be stopped and confidence must be built up. For the Dalai Lama side, he has to understand that it is hardly possible to give some special or more autonomous power only to Tibet in a country where there are quite a number of ethnic minorities. The equality of all ethnic minorities must not be undermined. Meanwhile, it is unfeasible that Tibetan people enjoy more political, cultural and religious rights and freedom than most other Chinese. The rights and freedom enjoyed by people of Hong Kong and Macao are not likely to be granted to the Tibetans.

When discussing any possibility to change the current system of regional autonomy in Tibet, it should be remembered that so far the Central Government has not yet opened the door to negotiate this issue with Dalai Lama. It is true that the Central Government has met with the'private representatives' of Dalai Lama for seven times, but it asserts that its contacts and dialogues with the representatives of Dalai Lama were about Dalai Lama's personal future, not so-called "China-Tibet negotiation" or "dialogue between Han and Tibetan people" because Dalai Lama no longer represents the Tibetans. The Central Government does not believe that Dalai Lama advocates the nonviolence policy. It continues to portrait Dalai Lama as a separatist, who orchestrated the violent activities of the radical Tibet Youth Congress. However, there are also some scholars who suggest that the Central Government should take advantage of Dalai Lama's present situation to reach out a solution on the Tibet issue.

\section{Conclusion}

Tibet has been part of China for hundreds of years. Before the 1950s Tibet was allowed to follow its own special political, social and religious system. The current system of regional ethnic autonomy is China's way to deal with its national issues. Basically this system is successful especially in the last 30 years. The Tibetans have witnessed marked progress and prosperity in economic, social, cultural and religious fields under the current autonomy. The dissatisfaction of the 14th Dalai Lama and his supporters deserves sympathy mainly when the situation of Tibet in the Cultural Revolution from the middle of the 1960s to the end of the 1970s is considered. In recent years, especially after the disintegration of the Soviet Socialist Union, the Central Government of China has been paying great attention to the protection and respects of the rights of all ethnic minorities including the Tibetans. A lot of progress has been achieved in improving the 
Tibetan people's life. The Central Government has resumed negotiation with the representatives of the 14th Dalai Lama. One of the current issues debated most was the extent to which the Tibetans should actually enjoy autonomy in the current autonomous region. The Tibetan people's feelings and demands on religious and cultural rights and freedom require more understanding from other Chinese people who believes in atheism. To solve the Tibet issue requires great courage and wisdom from the Chinese Central Government on one hand, and needs more understanding and wiser consideration from Dalai Lama on the other hand. Now there still exists sharp difference between the Central Government and the Tibet'government-in-exile.' There is still a long way to go before a real accord is reached between the Central government and Dalai Lama in exile. 